\title{
News \\ Parent cop vs parent coach: repairing the tear in parenting styles
}

Volume I Issue 4 - 2014

\author{
Steven Richfield \\ Clinical Psychologist, Philadelphia, USA
}

\author{
Correspondence: Steven Richfield, Clinical Psychologist, \\ Philadelphia, USA, Tel 6I0-238-4450, \\ Email director@parentcoachcards.com
}

Received: July 25, 2014 | Published: July 26, 2014 by learning how to observe ourselves in order to upgrade our skills. Narrowly defined, it's a problem that frequently surfaces when we contend with our children's challenging behavior: parents with conflicting styles. It may be a conflict over how to discipline, or when to discipline or even what warrants discipline.

In many cases, the conflict between parenting styles is more encompassing: one parent believes in coaching while the other leans more toward policing.

Most parents are familiar with policing kids or what I call the parentcop role. We may step into this role when our kids are creating any sort of pressing problem and we are hard pressed to find any available patience in deal with it. In our home, my wife and I refer to this situation as the "blinking parent warning light". It warns us, the parents, that our reacting sides are about to grab control over our handling of the situation, inevitably leading to the emergence of the parentcop, and as much as we try to hang on tight to our coaching caps, the currents of family life with two rambunctious boys can test our coaching resolve. Especially if one of our parenting triggers are present, we try hard to prevent the parentcop from emerging.

Parentcops are too quick to haul kids in for questioning, sentencing, and punishing. Yelling, idle threats of very serious consequences and other intimidation tactics also fall within the reactionary repertoire of parentcops. But interestingly, I've found that too much of the parentcop approach usually backfires: it actually produces more rule breaking on the part of kids because of the reservoir of anger that policing leaves inside of them. Here's the reason why: kids with strong-willed temperaments tend toward noncompliance, increased aggression, decreased tolerance for frustration, and peer difficulties. When parents jump into the parentcop role, they use harsh forms of discipline that may or may not include physical punishment. This leads to a temporary inhibition of the negative behavior, which in turn reinforces the parents use if it. But this leaves a residue of anger inside the child which is followed up by more harsh responses on the parents' part, and then another temporary delay as the cycle repeats itself.

Even if this cycle is only rarely present in our homes it's important to understand how we can easily get trapped inside of it when our kids act out. Just in case you're wondering, one way it can show up is with kids who are intimidated enough to follow the rules when we're watching but let loose their anger and impulses when we're not around! This is not the kind of situation that produces self-controlled kids but instead, kids who control themselves solely out of fear of consequences.

When policing, parents adopt a harsh, adversarial stance with children. Our volume and tone of voice, our facial expression, our choice of words, even our body posture communicates a "me vs. you" relationship - exactly the opposite of what our children need, especially young children who have great difficulty holding on to a perspective of us as loving parents when we are relating to them through the parentcop role. This situation is exceedingly painful for our children to endure, and often time leaves us feeling just as broken up inside. And yet, it is just this situation of one parent too quickly stepping into the parentcop role, while the other holds more tightly onto the coaching role that is at the root of the typical inconsistency and conflict of parenting approaches between mother and father.

In certain homes where this role distinction is stretched very far, children have told me that they feel like they have two families under one roof; two sets of rules; two sets of punishments; and two types of feelings that live inside - good and bad. No doubt that this situation shakes up kids' feelings of security pits parents against one another and undermines each other's role. And, of course, this situation makes parenting even more challenging, which is why I want to spend some time discussing what to do about this fairly typical problem that gets in the way of a unified parenting approach no matter how old our kids It is for all of us to watch out for our parenting triggers. To better illustrate how we can do this I have prepared a checklist that we can use. Here it is:

\section{Check off your parenting triggers and their intensity ( $1-5)$}

Key: $1=$ Mild $2=$ More than Mild $3=$ Moderate $4=$ Potent $5=$ Maximum WHEN MY CHILD IS VERBALLY DISRESPECTFUL CHILD

WHEN MY CHILD PURPOSEFULLY HITS ANOTHER REQUEST

WHEN MY CHILD DELIBERATELY DISOBEYS MY WHEN MY CHILD EMBARRASSES ME IN PUBLIC

WHEN MY CHILD SHOWS NO REMORSE FOR HIS/HER IMPROPER BEHAVIOR 
WHEN MY CHILD ACTS LIKE HE/SHE IS SPOILED

WHEN MY CHILD COMMITS THE SAME MISTAKE OVER AND OVER AGAIN (DOESN'T LEARN FROM MISTAKES)

\section{WHEN MY CHILD LIES TO ME OR OTHER ADULTS}

\section{WHEN MY CHILD IS UNWILLING TO ACCEPT BLAME} TOWARDS ME

WHEN MY CHILD IS PHYSICALLY AGGRESSIVE

The objective is to give parents a starting point for self and mutual assessment - or what I refer to as the "parenting review". Parents are asked to endorse each of the ten items with a number from 1-5 that indicates the strength of each trigger. The list is by no means exhaustive and can be added to. The other way it can be used is for parents to fill it out on each another, and then compare answers, to see how close your own assessments come to those of our spouse. One of the advantages of having both parents rate each other with this checklist is the productive discussion that will hopefully ensue. But keep in mind, timing is everything. It is much better to review these issues in a calm, objective atmosphere when the kids are occupied or asleep and you and your spouse can reflect upon your parenting roles. But as is the case with the Parent Coaching Cards, don't use this as an opportunity to criticize. Don't launch into parentcop bashing but instead offer your own self-assessment. Point out your areas of potent and maximum intensity (the top hot spots), and suggest why this may be the case.

A truly productive parenting review can lead to identifying issues about each other that will help both of you align a unified parenting approach. Some parents are less likely to use the checklist to take an objective look at their parenting style or inventory of skills. When that happens it can get very frustrating for the one parent who sees more clearly where improvement is needed. What do I recommend in a situation like this? Try approaching your spouse with your concerns without any hint of criticism. Ask them to assess you using the checklist. For example, one couple were so far apart on the parenting dimension between coaching and policing that the husband gave his wife all one's on the checklist. This allowed them to discuss how he saw her as not being firm enough - and she ultimately agreed with him. She agreed to become more firm if he would become a little less so - and they found a way to eventually meet in the middle. Other couples don't succeed as easily and kids and parents ultimately suffer as a result. But sometimes the red flags can help lead to resolution of parenting differences.

One red flag to look out for is when one of you tries to counterbalance the parenting style of the other. An example might be the parent who becomes more indulgent of the child's wishes for toys and treats to compensate for the firmer, authoritative stance of the other parent. If this is you don't wait for your spouse to accuse you of spoiling your child, express your concern that both of you may be trying to make up for the excesses you see in each other, but it's having a very confusing and polarizing effect upon your child.

Another red flag is in the discipline area: look out for signs of disciplinary dissent. This means that one of you punishes more severely than the other. The less firm parent may be unwilling to enforce the consequence, undermining the authority of the firmer parent, and thereby diminishing parental authority in the child's mind.

Both of these situations can be the catalyst for finding a middle ground in your parenting styles. But be sure that you use verbal diplomacy when discussing these emotionally charged issues.
Remember that the goal is to identify those issues that form barriers in our roles as parents. Barriers get in the way of our seeing our child accurately or responding empathically because there is something about ourselves that is interfering with this clarity of perspective. Another tool that I use to help parents identify important barrier issues are specialized coaching cards. Here is one:

\section{See into your parenting blind spots}

Every parent can strive to consider how personal issues shape parenting. The past and the present combine to effect how successful we are as parents. Consider the following:

- What good and bad experiences from my own childhood may continue to show up in my parenting?

- How free am I in my present life to parent effectively?

Try to be honest when answering these questions. The answers help reveal your strengths and weaknesses as a parent. The more you can open your mind to this self-awareness the more you can make choices to enhance your parenting. Without awareness of the truthful answers, parenting blind spots can interfere. Blind spots occur when we avoid accepting certain truths about ourselves, and set the stage for letting our own personal issues interfere.

Here are some typical signs of blind spots:

- Over-estimating how much of a parenting load I can handle before I become overwhelmed and resentful.

- Viewing my child as guilty of some inappropriate behavior without questioning how much I have precipitated it.

- Not accessing learning from past parenting mistakes, and repeating them without realizing I am doing so.

Here's another one:

\section{What's the coaching response?}

It happens when I'm least expecting it: one of my kids does or says something that targets one of my hot spots. If I allow it, my reacting side can take control and cause more conflict. In order to prevent that from happening I need to identify my hot spots and plan ahead for their management. Here are some of mine: when my older son purposefully injures my younger son; when my child takes chances with someone else's safety; and when my child fails to take responsibility for an error in judgment.

When these or other triggers occur, I need to follow the coaching approach:

1. Take a few deep breaths.

2. Make gentle physical contact with my child if s/he will accept it.

3. Ask them to tell me their side of the story.

4. When they are done, offer "I understand your side".

5. Suggest, "We both can learn something from what happened".

6. Proceed with reviewing the different contributions to the event; suggest, "The Coaching Cards may help us figure this out".

Parenting often leads us directly to our hot spots. This is due to our expectations and emotions that we wrap tightly around our children's behavior. When they act out in some inappropriate way, we are at risk for losing control over our reacting sides. Of course, this doesn't help 
us to guide them but it may reduce our credibility as authority figures. The coaching approach stresses the larger picture surrounding the circumstances. Rather than narrowly respond to the behavior, search for the underlying factors that led to the behavior. In this way, the discussion proceeds more like information gathering rather than an accusation.

\section{Conflicts of interest}

Author declares there are no conflicts of interest.

\section{Funding}

None.

\section{Acknowledgments}

None. 